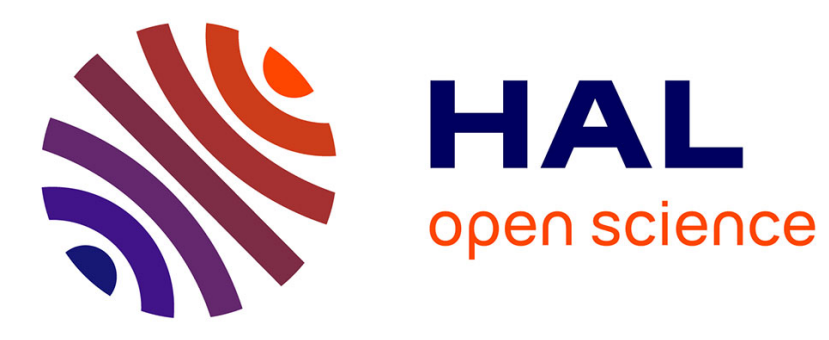

\title{
Morphology control of self-organised Sr3V2O8 nanostructures on SrVO3 grown onto single and poly-crystalline subjacent $\mathrm{SrTiO} 3$ substrates
}

B. Bérini, M. Dallocchio, A. David, U. Luders, Bourlier Yoan, L. Rault, Rosine Coq Germanicus, Wilfrid Prellier, Y. Dumont, Valérie Demange, et al.

\section{- To cite this version:}

B. Bérini, M. Dallocchio, A. David, U. Luders, Bourlier Yoan, et al.. Morphology control of selforganised Sr3V2O8 nanostructures on SrVO3 grown onto single and poly-crystalline subjacent SrTiO3 substrates. Applied Surface Science, 2021, 566, pp.150759. 10.1016/j.apsusc.2021.150759 . hal03335293

\section{HAL Id: hal-03335293 \\ https://hal.science/hal-03335293}

Submitted on 15 Sep 2021

HAL is a multi-disciplinary open access archive for the deposit and dissemination of scientific research documents, whether they are published or not. The documents may come from teaching and research institutions in France or abroad, or from public or private research centers.
L'archive ouverte pluridisciplinaire HAL, est destinée au dépôt et à la diffusion de documents scientifiques de niveau recherche, publiés ou non, émanant des établissements d'enseignement et de recherche français ou étrangers, des laboratoires publics ou privés. 


\section{Morphology control of self-organised $\mathrm{Sr}_{3} \mathrm{~V}_{2} \mathrm{O}_{8}$ nanostructures on $\mathrm{SrVO}_{3}$ grown onto single and poly-crystalline subjacent $\mathrm{SrTiO}_{3}$ substrates}

Bruno Bérini ${ }^{1, *}$, Marie Dallocchio ${ }^{2}$, Adrian David ${ }^{2}$, Ulrike Lüders ${ }^{2}$, Yoan Bourlier ${ }^{1}$, Ludivine Rault $^{3}$, Rosine Coq Germanicus ${ }^{2}$, Wilfrid Prellier ${ }^{2}$, Yves Dumont ${ }^{1}$, Valérie Demange ${ }^{3, *}$ and Arnaud Fouchet ${ }^{2, *}$

${ }^{1}$ Université Paris-Saclay, UVSQ, CNRS, GEMaC, 45 avenue des Etats-Unis, 78035, Versailles, France

${ }^{2}$ Normandie Univ, ENSICAEN, UNICAEN, CNRS, CRISMAT, 14000 Caen, France

${ }^{3}$ Univ Rennes, CNRS, ISCR - UMR 6226, ScanMAT - UMS 2001, F-35000 Rennes, France

Keywords: $\mathrm{SrVO}_{3}(\mathrm{SVO})$, strontium vanadate, transparent conducting oxide, combinatorial substrate epitaxy (CSE), nanostructure (NS)

\section{Corresponding authors}

Dr. Bruno Bérini ; Université Paris-Saclay, UVSQ, CNRS, GEMaC, 45 avenue des Etats-Unis, 78035, Versailles, France.

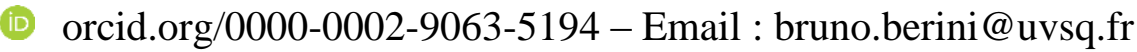

Dr. Valérie Demange ; Université Rennes, CNRS, ISCR - UMR 6226, ScanMAT - UMS 2001, F-35000 Rennes, France.

orcid.org/0000-0002-8153-2660 - Email : valerie.demange@univ-rennes1.fr

Dr. Arnaud Fouchet ; Normandie Université, ENSICAEN, UNICAEN, CNRS, CRISMAT, 14000 Caen, France.

orcid.org/0000-0002-3604-4756 - Email : arnaud.fouchet@ensicaen.fr 


\begin{abstract}
:
$\mathrm{SrVO}_{3}(\mathrm{SVO})$ is a complex oxide with interesting optical and conduction properties as an indium-free transparent conducting oxide for electrode applications. In this paper, we report how the surface of SVO can be designed at the nanoscale from self-organized $\mathrm{Sr}_{3} \mathrm{~V}_{2} \mathrm{O}_{8}$ nanostructures (NS) with different shapes and morphologies depending on crystalline orientations. By combining transmission electron microscopy (TEM) and atomic force microscopy (AFM), we compare the characteristics of the NS for SVO films grown on $\mathrm{SrTiO}_{3}$ (STO) polycrystalline substrates, according to combinatorial substrate epitaxy (CSE), with those of NS observed from SVO films deposited on STO single crystalline substrates with different crystallographic orientations ((100), (110), (111)). We are able not only to show that the obtained morphologies are correlated to the specific substrate orientation due to the epitaxial relationships between the NS, the SVO, and the substrate, but also to establish a NS library and determine the necessary crystalline orientations for a certain NS morphology on demand. Finally, dissolution of the NS in water leads to typical inverse imprints on the surface of the film, offering a fast and easy way to pattern the electrodes. This work presents a new way of patterning surfaces with a specific design of self-organized NS.
\end{abstract}

\title{
Introduction
}

Ternary oxides $\left(\mathrm{ABO}_{3}\right)$ with perovskite structure form a class of materials rich of various functional properties (piezoelectricity, ferroelectricity, superconductivity, etc.) ${ }^{1-5}$. This diversity is due to the wide range of cation sizes and the electronic filling of the $d$ orbitals possible to be accommodated in the perovskite structure, which both modify their crystalline structure and the electronic properties. For example, by substituting the cation $\mathrm{X}(\mathrm{X}: \mathrm{Ti}, \mathrm{V})$ in the formula $\mathrm{SrXO}_{3}$, we obtain respectively $\mathrm{SrTiO}_{3}$ ( $\mathrm{STO}$ with $3 d^{0}$ ) which is insulator and frequently used as substrate for all-oxides heterostructures ${ }^{4}$ and $\mathrm{SrVO}_{3-\delta}$ ( $\mathrm{SVO}$ with $3 d^{1-\delta}$ ) which is a metal and can be used as an electrode for integration of functional oxides ${ }^{6-8}$. This metallic behavior is also associated to a high optical transparency in the visible range due to electronic correlations, which makes SVO interesting as a new transparent conductor oxide ${ }^{9-13}$. Interestingly, both of these materials possess the same primitive cubic structure (space group $P m \overline{3} m, \mathrm{~N}^{\circ} 221$ ) with lattice constant $a=3.905 \AA{ }^{14}$ (STO) and $3.843 \AA$ for $\delta=0$ and $3.856 \AA$ for $\delta=0.1(\mathrm{SVO})^{15-18}$, respectively. The similar lattice parameter in these compounds allows the vertical integration of the perovskite family through epitaxy $y^{19,20-22}$. 
$\mathrm{SVO}$ is usually grown at low oxygen pressure to stabilize the $\mathrm{V}^{4+}$ state since vanadium is highly sensitive and more stable in the $\mathrm{V}^{5+}$ state $\left(3 d^{0}\right)$. Therefore, films are typically grown under vacuum or in a low $\mathrm{O}_{2}$ partial pressure (less than $1.2 \times 10^{-4} \mathrm{~Pa}$ at $750^{\circ} \mathrm{C}$ ) and rapidly cooled under vacuum to avoid the appearance of higher vanadium valence state phases such as insulating $\mathrm{Sr}_{3} \mathrm{~V}_{2} \mathrm{O}_{8}$. This phase appears in the form of elongated nanostructures (NS) ${ }^{23,24,10}$, with an epitaxial relationship to the SVO matrix, as it was shown in the case of (100)-oriented SVO films ${ }^{25,26}$. Furthermore, the NS have the particularity to grow also inside the SVO matrix, i.e. the NS are half buried down to the SVO film surface. Interestingly, the NS phase is highly soluble in water, leaving after dissolution imprints with a depth from 10 to $20 \mathrm{~nm}$ equal to their initial heights, building a network which can be useful for nano-patterning ${ }^{27}$. Therefore, nanopatterned electrodes can be developed for the integration of complex oxides promoting the development of devices or sensors at the nanoscale. As a promising transparent conductive oxide (TCO), such particular SVO surface can also be tailored to obtain very high surface area in optical devices. Finally, nanostructured surfaces can be used for different applications such as optical anti-reflective applications ${ }^{28}$ or surface nano-structure-wettability ${ }^{29}$.

Up to now, only elongated NS with two variants being oriented by $90^{\circ}$ have been reported for SVO. Nevertheless, it would be useful to obtain different NS shapes, sizes and spatial distributions, in order to create other patterns which can be adaptable on request. As the NS are epitaxially grown on SVO, their characteristics and epitaxial relations should be related to the lattice misfit with respect to the SVO matrix. So the crystalline orientation of the SVO matrix becomes an important lever for the diversification of the NS shapes. In this study, we use polycrystalline substrates based on the combinatorial substrate epitaxy (CSE) approach in order to provide a full investigation of the different NS which can be obtained based on the crystalline orientations of the SVO matrix. In those polycrystalline substrates, each grain acts as a single crystal for the growth of the thin film ${ }^{30-37}$, so that all crystalline orientations of the SVO film can be obtained with only one substrate. These substrates can be synthetized from exotic materials with different structures not commercially available ${ }^{30,31,35}$. In the case of STO, atomically flat surfaces can be obtained ${ }^{36}$ and also that the size of each grains can be tuned from 1 to $40 \mu \mathrm{m}$ depending on the annealing process. Additionally to low production costs compared to single crystalline substrates, these substrates may provide also the possibility of engineering physical properties of thin films via grain boundaries, in order to improve the thermoelectric ${ }^{37}$ or magnetotransport properties, for example. 
In this paper, SVO films are grown on commercially STO single crystalline substrates with the produced $\mathrm{Sr}_{3} \mathrm{~V}_{2} \mathrm{O}_{8}$ surface NS are studied by transmission electron microscopy (TEM) and atomic force microscopy (AFM) relatively to their epitaxial relationship with respect to the SVO matrix orientation. Then, the use of CSE allows us to establish a complete library of the orientation-morphology relation of the $\mathrm{NS}^{36,38-40}$. This technique also reveals itself as a powerful tool to investigate the NS on the orientation of the SVO matrix underneath. Correlated to electron back scatter diffraction (EBSD) measurements, AFM imaging has been performed on selected grains to observe the morphologies and compare them to the three common orientations. Beyond these results, a "zoology" of these NS is presented, allowing to extract the necessary crystalline orientation from this library and adapt the NS shape and spatial orientation to the application requirements.

\section{Materials and methods}

STO polycrystalline substrates were synthesized by mixing the two precursors $\mathrm{TiO}_{2}$ and $\mathrm{SrCO}_{3}{ }^{36}$. After numerous machine and manual grinding steps, a calcination was performed at $1200{ }^{\circ} \mathrm{C}$ for 12 hours. After pressing, the pellets were sintered by spark plasma sintering (SPS) at $1500^{\circ} \mathrm{C}$ for $20 \mathrm{~min}$ in order to obtain a polycrystalline substrate with a grain size of around $40 \mu \mathrm{m}$. The ceramic was then polished in order to obtain mirror-like surface for the local epitaxy of the SVO film. First, we use a manual process with several SiC papers (30-15-10-5 $\mu \mathrm{m})$, then an automatic polishing (using a Struers polisher) with diamond liquid pastes (at $3 \mu \mathrm{m}$ and $1 \mu \mathrm{m}$ grain size) and the last step was a finishing process by $\mathrm{SiO}_{2}$-colloidal solution.

Three commercial (SurfaceNet GmbH) STO $\left(4 \times 4 \times 0.5 \mathrm{~mm}^{3}\right)$ substrates with the (100), (110) and (111) orientations were glued together with the polycrystalline STO substrate on the substrate holder with silver paste. The deposition of SVO films was performed at $850^{\circ} \mathrm{C}$ under $2.5 \times 10^{-6}$ mbar of oxygen pressure using the pulsed laser deposition (PLD) technique. A $\mathrm{KrF}$ laser $(\lambda=248 \mathrm{~nm})$ at an energy of $1.85 \mathrm{~J} / \mathrm{cm}^{2}$ and repetition rate of $2 \mathrm{~Hz}$ was used. The base pressure of the chamber was $5 \times 10^{-9}$ mbar and the distance between target and substrate approximately $5 \mathrm{~cm}$. A $60-\mathrm{nm}$ thick SVO film has been synthesized. After deposition, the samples were maintained 30 minutes at the growth temperature and oxygen partial pressure in order to form the NS, before being cooled down during 3 hours ${ }^{23}$. 
The polycrystalline substrates were investigated by scanning electron microscopy (SEM) and EBSD, with a Zeiss Supra 55 instrument. The conditions for EBSD were: V $=15 \mathrm{kV}$, aperture $=60 \mu \mathrm{m}$ and working distance $=15 \mathrm{~mm}$. Prior to deposition, the surfaces of the substrates were prepared by a $\mathrm{NH}_{4} \mathrm{~F}$ etching and an annealing at $950^{\circ} \mathrm{C}$ for $1 \mathrm{~h}$. Figure SI- 1 presents AFM images of a polycrystalline substrate for randomly selected areas after revealing terraces as presented in ref. ${ }^{36}$. Terraces are observed with dimensions related to the orientation of the different grains, which are randomly distributed.

Dissolution of the $\mathrm{Sr}_{3} \mathrm{~V}_{2} \mathrm{O}_{8}$ NS was realized by rinsing the substrates under water for $30 \mathrm{~s}$, and before drying with $\mathrm{N}_{2}$. To get a complete NS dissolution on the (111)STO substrate, a second irrigation with water for $30 \mathrm{~s}$ was used.

X-ray diffraction (XRD) analysis on the thin films was carried out using a $\theta-2 \theta$ instrument (Bruker AXS D8 Advance) working with a monochromatized $\mathrm{Cu}-\mathrm{K} \alpha 1$ radiation and equipped with a $1 \mathrm{D}$ detector (192 channels).

A Dimension ICON AFM (Bruker) has been used to observe morphology of NS present onto the surface of the various samples. The AFM topography measurements were performed in air with the PeakForce tapping mode. For this purpose, a silicon tip on nitride lever (ScanAsyst Air model, Bruker), with a $0.4 \mathrm{~N} / \mathrm{m}$ spring constant and a nominal tip radius of 2 $\mathrm{nm}$ was used with a resolution of 512 pixels $\times 512$ pixels.

TEM study on the SVO films grown on (100), (110) and (111)STO was performed by using a Jeol 2100 instrument operating at $200 \mathrm{kV}$ and equipped with a Gatan Orius 200D and a Gatan US Scan 1000 cameras. Samples for TEM were obtained by scratching the film with a diamond tip and the obtained fragments were collected on a commercial carbon-coated copper microgrid.

\section{Results and discussion}

\section{1. $\mathrm{Sr}_{3} \mathrm{~V}_{2} \mathrm{O}_{8}$ nanostructures growth on single crystalline (100), (110) and (111)STO substrates}

Figure 1 shows the surface of SVO thin films simultaneously grown on three common orientations of STO. Comparable to what we previously observed for $\mathrm{CaVO}_{3}{ }^{41}$, self-organized $\mathrm{Sr}_{3} \mathrm{~V}_{2} \mathrm{O}_{8} \mathrm{NS}$ are observed in the analyzed regions of $4 \times 4 \mu \mathrm{m}^{2}$ with a morphology being function of the substrate orientation. On (100)STO, the surface presents elongated shapes of $160 \mathrm{~nm}$ 
length and $75 \mathrm{~nm}$ width with an average height of $25 \mathrm{~nm}$ (figure 1a). The root mean square oxygen pressure during the growth and to an increased waiting time before cooling. The NS follow two perpendicular in-plane directions as already described in a previous study. ${ }^{24}$ These $\mathrm{Sr}_{3} \mathrm{~V}_{2} \mathrm{O}_{8}$ NS with similar shape have also been reported on (100) $\mathrm{NdGaO}_{3}$ (NGO) and $(100)\left(\mathrm{LaAlO}_{3}\right)_{0.3}\left(\mathrm{Sr}_{2} \mathrm{AlTaO}_{6}\right)_{0.7}$ (LSAT) substrates ${ }^{11,42}$. Interestingly, on the (110)STO substrate, elongated NS can also be observed but they appear oriented along only one direction. The NS are a little longer than on (100)STO e.g. between 200 to $500 \mathrm{~nm}$-long (figure 1b) and have a $16 \mathrm{~nm}$-height. On (111)STO, two types of different NS appear: the first ones have triangular shape and the second ones are oblong NS as for (100)STO and (110)STO. Nevertheless, in this case, the oblong NS with variable size (50 to $250 \mathrm{~nm}$ ) are oriented with an angle of $60^{\circ}$ between them (figure 1c).

Figure 2 displays XRD patterns of films grown on (100)-, (110)- and (111)STO substrates. These patterns exhibit only the substrate Bragg peaks and the 100,110 and 111 reflections of the SVO phase, respectively, indicating that the substrates induce a preferential out-of-plane film orientation as expected for materials having the same structure type and similar lattice parameters. No secondary phases are found, neither peaks attributed to the $\mathrm{Sr}_{3} \mathrm{~V}_{2} \mathrm{O}_{8}$ NS due to a too small diffracting volume. The out-of-plane lattice constant of the SVO phase is $a=3.841$ $\AA$, $3.845 \AA$ and $3.845 \AA$ on (100)-, (110)- and (111)STO, respectively, close to the bulk values. To estimate the quality of our metallic samples, we use the residual resistivity ratio (RRR) ${ }^{8,11}$ criteria, which is sensitive to defects as cation non-stoichiometry, oxygen deficiency or disorder, especially for SVO grown on STO substrates for which the lattice mismatch $f$ is large $\mathrm{e}^{10,11}(f(\mathrm{STO})=+1,59 \%$ is larger than $f(\mathrm{LAO})=-1,37 \%$, larger than $f(\mathrm{LSAT})=+0,65 \%$, larger than $f(\mathrm{NGO})=+0,52 \%)$. The following values of RRR were deduced from transport measurements in the range 2-300 K: 2.47 (STO100), 2.59 (STO110) and 2.73 (STO111), indicating a high quality of the SVO films on STO whatever their orientation.

In order to understand the different morphologies and shapes of the NS, we have investigated the epitaxial relationships between the NS and SVO by TEM measurements. Figure 3 displays electron diffraction patterns (EDP) of SVO films grown on the different STO substrates. For the film grown on (100)STO, EDP are taken along the [100] zone axis of the SVO phase. With the strong reflections of the SVO film, weak reflections from the two elongated $\mathrm{Sr}_{3} \mathrm{~V}_{2} \mathrm{O}_{8}$ variants are observed as depicted by the white square in the figure $3 \mathrm{a}$. The intensity of these reflections is enhanced after a slight tilt of the sample (see figure $3 \mathrm{~b}$ ) and 
additional reflections, due to the double-diffraction phenomena between two phases having the orientation of the NS was determined from indexation of these reflections as being $[\overline{5} 52] \mathrm{Sr}_{3} \mathrm{~V}_{2} \mathrm{O}_{8}$ direction parallel to the [100]SVO direction ${ }^{23,24}$. Comparison between pattern of $\mathrm{Sr}_{3} \mathrm{~V}_{2} \mathrm{O}_{8}$ and that of SVO confirms the previously established epitaxial relationships between the two vanadates ${ }^{23,24}$, which are $[\overline{5} 52] \mathrm{Sr}_{3} \mathrm{~V}_{2} \mathrm{O}_{8} / /$ [100]SVO, (110) $\mathrm{Sr}_{3} \mathrm{~V}_{2} \mathrm{O}_{8} / /(011) \mathrm{SVO}$ and $(\overline{1} 1 \overline{5}) \mathrm{Sr}_{3} \mathrm{~V}_{2} \mathrm{O}_{8} / /(01 \overline{1}) \mathrm{SVO}$. The orientation of the $\mathrm{Sr}_{3} \mathrm{~V}_{2} \mathrm{O}_{8}$ cell with respect to that of SVO is schematized on the figure $4 \mathrm{a}$. In this scheme, the coincidence lattice between both phases is drawn by a red square. In particular, the $\mathrm{d}(110)_{\mathrm{Sr} 3 \mathrm{~V} 2 \mathrm{O} 8}$ inter-planar distance $(2.81 \AA)$ is close to the $\mathrm{d}(110)_{\text {Svo }}$ and $\mathrm{d}(\overline{1} 10)_{\text {Svo distances }}(2.71 \AA$ ) leading to two equiprobable possibilities for $\mathrm{Sr}_{3} \mathrm{~V}_{2} \mathrm{O}_{8}$ to grow on $\mathrm{SVO}$, i.e. (110) $\mathrm{Sr}_{3} \mathrm{~V}_{2} \mathrm{O}_{8} / /$ (110)SVO and (110) $\mathrm{Sr}_{3} \mathrm{~V}_{2} \mathrm{O}_{8} / /(1 \overline{1} 0) \mathrm{SVO}$, and therefore to the formation of elongated NS $90^{\circ}$ rotated with respect to each other. The mismatches between $\mathrm{SVO}$ and $\mathrm{Sr}_{3} \mathrm{~V}_{2} \mathrm{O}_{8}$ are equal to $-3.69 \%$ for one in-plane directions and $14.39 \%$ in the other one. In addition, high resolution TEM (HRTEM) was performed on the SVO film. Figure SI-2a is a bright field image of an edge of a fragment showing NS which partially extend underneath the (100)SVO film. Therefore, HRTEM image of a NS without subjacent SVO film is recordable in such area, as displayed on figure SI-2b. Fast Fourier Transform (FFT) of this area shows a rectangular array corresponding to the [ $\overline{5} 52]$ zone axis of the $\mathrm{Sr}_{3} \mathrm{~V}_{2} \mathrm{O}_{8}$ phase (figure SI-2c), while the FFT of the SVO film next to it shows a square pattern. This result confirms the previously evidenced epitaxial relationship. The area where the NS is lying on the perovskite displays a Moiré contrast due to the superposition of the lattices and its FFT displays additional reflections due to these fringes (figure SI-2c). Similar analysis was done for the film grown on (110)STO (see figures 3c,d). A slight tilt of the [110]SVO zone axis allows to see additional reflections due to the $\mathrm{Sr}_{3} \mathrm{~V}_{2} \mathrm{O}_{8} \mathrm{NS}$, as depicted by the square in figure $3 \mathrm{c}$ and magnified in the inset. Indexation of these reflections highlights that the phase is oriented along the [55 4 ] zone axis, as schematized on the figure $3 \mathrm{~d}$. The 110 reflections are in coincidence with the $1 \overline{1} 0$ reflections of SVO, while the $(2 \overline{2} \overline{5})$ planes are parallel to the (001) planes of SVO. The corresponding orientation of the $\mathrm{Sr}_{3} \mathrm{~V}_{2} \mathrm{O}_{8}$ cell with respect to that of the $\mathrm{SVO}$ cell is schematized in figure $4 \mathrm{~b}$. The mismatches between $\mathrm{Sr}_{3} \mathrm{~V}_{2} \mathrm{O}_{8}$ and SVO are equal to $-3.69 \%$ for the first in-plane direction and $-8.33 \%$ for the second one, if the red subunit cells displayed in figure $4 \mathrm{~b}$ are considered. The orientation of $\mathrm{Sr}_{3} \mathrm{~V}_{2} \mathrm{O}_{8}$ with respect to the SVO phase leads to the following epitaxial relationships between the two vanadates: 
$[5 \overline{5} 4] \mathrm{Sr}_{3} \mathrm{~V}_{2} \mathrm{O}_{8} / /[110] \mathrm{SVO}$

(110) $\mathrm{Sr}_{3} \mathrm{~V}_{2} \mathrm{O}_{8} / /(1 \overline{1} 0) \mathrm{SVO}$

$(2 \overline{2} \overline{5}) \mathrm{Sr}_{3} \mathrm{~V}_{2} \mathrm{O}_{8} / /(001) \mathrm{SVO}$

Interestingly, as the in-plane directions of the (110)SVO are anisotropic, only one type of NS appears along the [110] in-plane direction compared to (100)SVO, which shows orthogonal NS. Figure SI-2d is a HRTEM image of a NS onto (110)SVO. The SVO film is visible in the top right corner of this image, while the $\mathrm{Sr}_{3} \mathrm{~V}_{2} \mathrm{O}_{8}$ is visible in the remaining part of the image, with Moiré fringes. FFT of this area (figure SI-2e) displays reflections of both phases with the same orientations as on the EDP displayed on figure 3c. From these results, the elongation direction of the NS is determined as being [110].

Figures 3e,f give the EDPs of (111)SVO, showing the strong reflections of the perovskite phase together with weaker reflections due to the elongated NS. Tilting the sample allows to see three different variants of the $\mathrm{Sr}_{3} \mathrm{~V}_{2} \mathrm{O}_{8}$ phase with the [55 1 ] out-of-plane direction, and an epitaxial growth due again to the fact that the inter-planar distance $d(110)$ of $\mathrm{Sr}_{3} \mathrm{~V}_{2} \mathrm{O}_{8}$ is close to $d(\overline{1} 10)$ of SVO. Since along the [111] zone axis, this distance is equivalent to the $d(01 \overline{1})$ and $d(10 \overline{1})$ distances, this leads to the formation of three elongated variants rotated by $60^{\circ}$ with respect to each other, as displayed in the AFM image (figure 1c). Figure $3 \mathrm{~g}$ shows a scheme of the EDP with the reflections of the SVO film and those of one variant, while the figure $3 \mathrm{~h}$ displays the scheme of the EDP with the three variants. The epitaxial relationships are:

$[5 \overline{5} 1] \mathrm{Sr}_{3} \mathrm{~V}_{2} \mathrm{O}_{8} / /[111] \mathrm{SVO}$

$(\overline{1} \overline{1} 0) \mathrm{Sr}_{3} \mathrm{~V}_{2} \mathrm{O}_{8} / /(\overline{1} 10) \mathrm{SVO}$

$(\overline{1} 05) \mathrm{Sr}_{3} \mathrm{~V}_{2} \mathrm{O}_{8} / /(01 \overline{1}) \mathrm{SVO}$

The corresponding cell orientations are schematized on the figure 4c-II-elongated nanostructures. The mismatches between $\mathrm{SVO}$ and $\mathrm{Sr}_{3} \mathrm{~V}_{2} \mathrm{O}_{8}$ are equal to $-3.69 \%$ for the first in-plane direction and $-14.39 \%$ for the second one.

In order to investigate the hexagonal NS, another area of the (111)SVO film grown on (111)STO was investigated as seen on figure 5. On the bright field image displayed on figure 5a, one can observe the triangular-shaped $\mathrm{Sr}_{3} \mathrm{~V}_{2} \mathrm{O}_{8}$ crystallites which have a slightly darker contrast than the SVO matrix. Since the $\mathrm{Sr}_{3} \mathrm{~V}_{2} \mathrm{O}_{8}$ phase possesses the rhombohedral symmetry, it comes from theses crystallites have grown with the following relationships: [001] $\mathrm{Sr}_{3} \mathrm{~V}_{2} \mathrm{O}_{8}$ (in hexagonal settings) // [111]SVO. Since the inter planar distances $d(1 \overline{1} 0) \mathrm{SVO}=2.71 \AA$ and 
$\mathrm{d}(110) \mathrm{Sr}_{3} \mathrm{~V}_{2} \mathrm{O}_{8}=2.81 \AA$ are very close, the reflections of the orthovanadate are not visible on the corresponding EDP (figure 5b). These epitaxial relationships, schematized on figures 4c-Itriangular nanostructures, are:

$[001] \mathrm{Sr}_{3} \mathrm{~V}_{2} \mathrm{O}_{8} / /[111] \mathrm{SVO}$

(110) $\mathrm{Sr}_{3} \mathrm{~V}_{2} \mathrm{O}_{8} / /(\overline{1} 10) \mathrm{SVO}$

$(2 \overline{1} 0) \mathrm{Sr}_{3} \mathrm{~V}_{2} \mathrm{O}_{8} / /(01 \overline{1}) \mathrm{SVO}$

The bright field image after tilting of the sample (figure 5c) shows dense Moiré fringes in the whole area indicating a large coverage of the triangular-shaped crystallites on the SVO film as evidenced by AFM (figure 1c). For this out-of-plane orientation, the mismatch between $\mathrm{SVO}$ and $\mathrm{Sr}_{3} \mathrm{~V}_{2} \mathrm{O}_{8}$ is equal to $-3.69 \%$ for the three equivalent in-plane directions. Concerning the elongated crystallites, some of them are visible on the bright field image displayed on figure $5 \mathrm{~d}$, with a dark contrast under some peculiar misorientations with respect to the zone axis. Since the lattice mismatch is similar for all the directions, this maybe explains why the elongated NS are less numerous (as they are anisotropic) than the triangular-shaped crystallites as it can be seen on figure 1c. Figure SI-2f is a HRTEM image of an elongated $\mathrm{Sr}_{3} \mathrm{~V}_{2} \mathrm{O}_{8}$ NS on (111)SVO. The superposition of the lattice of this NS onto the SVO film involves Moire fringes on the image. FFT of the $\mathrm{Sr}_{3} \mathrm{~V}_{2} \mathrm{O}_{8}$ area shows additional reflections compared to the FFT of the SVO film alone (figure SI-2g) as observed on the EDP on figure 3e,f, with reflections due to the Moiré fringes. All these measurements have shown the different epitaxial relationships of the NS on the different orientations of the SVO matrix. As this SVO film can be tuned with different crystallographic directions, it results different configurations of the elongated NS: alignment along only one direction of all the NS for (110)SVO, NS orthogonal alignment with (100)SVO and finally $60^{\circ}$ from each other with the (111)SVO. Furthermore for the (111)SVO another type of NS is stabilized with triangular shape due to strain effect.

In order to observe the different NS, fragment of SVO images have been investigated in bright and dark field for all the orientations (figure SI-3). These analyses confirm that the additional reflections observed in the EDPs are due to the NS.

From these crystallographic and epitaxial analyses, some elements can be given relative to the formation and growth of the $\mathrm{Sr}_{3} \mathrm{~V}_{2} \mathrm{O}_{8}$ nanostructures from the SVO matrix. Apparition of the nanostructures is a complex problem controlled by thermodynamic and kinetic driving forces 44-46. The $\mathrm{Sr}_{3} \mathrm{~V}_{2} \mathrm{O}_{8}$ nanostructures are generated by a structural phase transformation from cubic $\mathrm{SVO}$ to rhombohedral $\mathrm{Sr}_{3} \mathrm{~V}_{2} \mathrm{O}_{8}$ due to oxidation of the vanadium, which seems more stable at 
high temperature than the perovskite phase. The two phases $\mathrm{SVO}$ and $\mathrm{Sr}_{3} \mathrm{~V}_{2} \mathrm{O}_{8}$ present strong differences: compare to SVO with 6 atoms/cell (cubic phase $a=3.86 \AA$ ), the orthovanadate $\mathrm{Sr}_{3} \mathrm{~V}_{2} \mathrm{O}_{8}$ is a complex phase with 39 atoms/cell, with larger lattice constants $(a=5.62 \AA, c=$ $20.1 \AA$ ). In the diluted NS regime without coarsening, the energy E of a single NS is the sum of three contributions $E_{\text {surf }}$ the surface energy, $E_{\text {relax }}$ the elastic relaxation energy, and $E_{\text {edges }}$ the short range contribution of edges. Even if the surface energies of $\mathrm{Sr}_{3} \mathrm{~V}_{2} \mathrm{O}_{8}$ and SVO are not referenced to our knowledge, some statements can be done from comparative observation of NS formed in the same growth conditions.

In terms of relaxation energies, a summary of lattice misfits is given in table SI-1, and we observed in cases of elongated NS (for (100), (110) and (111) SVO matrices), that the longer direction is always [110] $\mathrm{Sr}_{3} \mathrm{~V}_{2} \mathrm{O}_{8}$. This is the direction where the compressive lattice mismatch is lower inducing elongated nanostructures ${ }^{45-47}$. Moreover, the orientations of the growth planes have been extracted from Fast Fourier Transform (FFT) of the TEM images: Figure SI_ 2 a,b,c for 100(SVO) orientation, Figure SI_2 d,e for 110(SVO) orientation and Figure SI_2 f,g for (111)SVO orientation, and figure 5a-b for triangular nanostructures. The results have been summarized in the table SI-2 and figures SI-4,5,6.

It results that the growth plane (110) $\mathrm{Sr}_{3} \mathrm{~V}_{2} \mathrm{O}_{8}$ is present for all elongated nanostructures and we can qualitatively conclude that the surface energy of the (110) $\mathrm{Sr}_{3} \mathrm{~V}_{2} \mathrm{O}_{8}$ growth plane is lower that other contributions and drives NS elongation mechanism.

For the (111)SVO orientation, the two types of nanostructure are observed (elongated and triangular one). In this case, there is a competition between the influence of the lattice mismatch and the surface energy of the growth planes.

An exact interpretation of all NS types in term of thermodynamics, needs both: a complete study of the coarsening of each NS with their fine geometry; and mechanical coefficient of materials, and abinitio calculations of surface energies of both materials. We hope that our present NS panorama for each (100), (110), and (111)SVO films will stimulate such $a b$ initio calculations. 


\section{2- $\mathrm{Sr}_{3} \mathrm{~V}_{2} \mathrm{O}_{8}$ nanostructures growth on a polycrystalline STO substrate}

As observed in the study on the single crystalline substrates, the shape and the orientation of the NS depend on the crystalline orientation of the SVO matrix through complex epitaxial relationships. In order to explore the different types of NS available on more exotic matrix orientations, we have grown a SVO thin film on a CSE STO substrate, and observed the nanostructures on different grain orientations.

Prior to film deposition, EBSD has been performed on the polycrystalline STO substrate in order to determine the different orientations of the grains. Red, green and blue colours correspond to (100)STO, (110)STO and (111)STO orientations, (see figure SI-7a). Other colours as yellow, purple, pink etc. are attributed to higher index orientations determined by the stereographic orientation. The same area was again investigated by EBSD after the SVO deposition (see figure SI-7b). For the determination of the grain orientation, the same crystallographic phase was used for STO and SVO (space group $P m \overline{3} m$ ). As it can be seen, the same colour code of the individual grains is obtained after the SVO deposition, indicating a coherent growth. Nevertheless, the NS are too small to be detected by EBSD. Therefore, AFM measurements have been performed on several grains having the different crystallographic directions determined by EBSD (see figure 6). The same letter has been assigned to each analysed grain on the EBSD map and on the AFM images (see figures 6 and figures SI-8 to 10). According to the stereographic projection unit, the grains coloured in red, green and blue are (100), (110) and (111) preferentially oriented, respectively, and the corresponding AFM images (figure 6) show that the NS morphologies and in-plane orientations are similar to those observed on figure 1, as expected. Therefore, the CSE STO polycrystalline substrate presents the same characteristics than single crystalline substrates and promotes locally the same epitaxy.

The NS grown on (100)-oriented grains present the same morphology with in-plane $90^{\circ}$ rotation relatively to each other in relation with the previously characterised epitaxial relationships. The difference in the in-plane rotation between each grain is related to the random orientation of the grains relatively to each other due to the polycrystalline nature of the CSE substrates. Nevertheless some NS size difference can also be observed depending on the individual grain although the same annealing time is simultaneously applied for all the grains. This effect could be attributed to small misorientations introducing miscuts on the surface which could modify the surface energy, the growth velocity and the shape of the NS compared to the single crystalline STO substrates. This statement is qualitatively supported by the small width of 
terraces observed on figure SI-1. For growth on (110)-oriented grains, (in green in figure 6),

\section{Dissolution of the nanostructures}

Figure 7 shows the AFM images of the films after water dissolution of NS for different substrate orientations. On single crystalline (100) and (110) STO substrates, clear imprint features are observed, associated to the previously presented NS that are half buried in the SVO matrix ${ }^{34,37}$. In case of the (111)STO substrate, the dissolution is incomplete with no clear evidence of imprints due to the presence of NS with their characteristic triangular form. Actually, an additional time of $30 \mathrm{~s}$ under water has been necessary to dissolve entirely the NS in this sample (figure SI-11) but still without clear imprints in the matrix. Only an elongated NS has left an imprint after dissolution as depicted by the red circle in figure SI-11. Therefore, the triangular shaped NS seem to grow on the surface of the SVO film, without the embedding in the matrix. 
For comparison, the dissolution of NS has been performed also on the polycrystalline substrate.

\section{CONCLUSIONS}

Oxidation of $\mathrm{SrVO}_{3}$ films leads to the growth of the orthovanadate $\mathrm{Sr}_{3} \mathrm{~V}_{2} \mathrm{O}_{8}$ phase in the form of NS, for which orientations depend on the orientation of the subjacent $\mathrm{SrTiO}_{3}$ substrate. Complex epitaxial relationships were evidenced for all the observed NS variants, with different crystallites shapes according to the out-of-plane and in-plane orientations: (i) on (100)STO, the $\mathrm{Sr}_{3} \mathrm{~V}_{2} \mathrm{O}_{8}$ phase grows as elongated NS along the [552] out-of-plane direction with two equivalent variants forming a $90^{\circ}$ angle; (ii) on (110)STO, the $\mathrm{Sr}_{3} \mathrm{~V}_{2} \mathrm{O}_{8}$ phase grows as elongated NS along the [5 $\overline{5} 4$ ] out-of-plane direction; (iii)on (111)STO, the $\mathrm{Sr}_{3} \mathrm{~V}_{2} \mathrm{O}_{8}$ phase grows as hexagonal-shaped crystallites along the [001] out-of-plane direction and also elongated NS along the [5 $\overline{5} 1]$ out-of-plane direction (3 variants). Such particular shapes of the NS are closely related to the initial orientation of the substrate. Furthermore, we are showing that polycrystalline substrates are a powerful tool to investigate a large diversity of NS depending on the orientation of the SVO matrix and provides a fast way to establish a NS library. Dissolution of the NS have also been performed confirming that most of the NS are partially buried in the matrix and typical imprints features can be rapidly obtained by controlling the rinsing time. This work presents a first step to the elaboration and design of self-organized NS in order to prepare particular surfaces with specific designs for future integration of SVO or to extend its use to new applications. 


\section{Acknowledgements}

The authors acknowledge the LabEx CHARMMMAT for financial support and the French Agence Nationale de la Recherche (ANR) (ANR-17-CE08-0012) in the framework of the POLYNASH project. TEM were performed on ScanMAT facilities platforms (UMS 2001, University of Rennes 1-CNRS). ISCR and ScanMAT received a financial support from the Region Bretagne, Rennes Metropole, the Departement d'Ille-et-Vilaine and the European Union (CPER-FEDER 2007-2014, Presage Nos. 39126 and 37339, and CPER 2015-2020 MULTIMAT ScanMAT). We thank the Région Normandie for the PlaceNano RIN project. 


\section{References}

(1) Coll, M.; Fontcuberta, J.; Althammer, M.; Bibes, M.; Boschker, H.; Calleja, A.; Cheng, G.; Cuoco, M.; Dittmann, R.; Dkhil, B.; El Baggari, I.; Fanciulli, M.; Fina, I.;

Fortunato, E.; Frontera, C.; Fujita, S.; Garcia, V.; Goennenwein, S. T. B.; Granqvist, C.-G.; Grollier, J.; Gross, R.; Hagfeldt, A.; Herranz, G.; Hono, K.; Houwman, E.; Huijben, M.; Kalaboukhov, A.; Keeble, D. J.; Koster, G.; Kourkoutis, L. F.; Levy, J.; Lira-Cantu, M.; MacManus-Driscoll, J. L.; Mannhart, J.; Martins, R.; Menzel, S.; Mikolajick, T.; Napari, M.; Nguyen, M. D.; Niklasson, G.; Paillard, C.; Panigrahi, S.; Rijnders, G.; Sánchez, F.; Sanchis, P.; Sanna, S.; Schlom, D. G.; Schroeder, U.; Shen, K. M.; Siemon, A.; Spreitzer, M.; Sukegawa, H.; Tamayo, R.; van den Brink, J.; Pryds, N.; Granozio, F. M. Towards Oxide Electronics: A Roadmap. Appl Sur Sci 2019, 482, 1-93. https://doi.org/10.1016/j.apsusc.2019.03.312.

(2) Rao, C. N. R. The World of Perovskite Oxides: From Dielectrics to Superconductors. Phys. C 1988, 153-155, 1762-1768. https://doi.org/10.1016/0921-4534(88)90470-4.

(3) Schlom, D. G.; Chen, L.-Q.; Pan, X.; Schmehl, A.; Zurbuchen, M. A. A Thin Film Approach to Engineering Functionality into Oxides. J. Am. Ceram. Soc. 2008, 91 (8), 2429-2454. https://doi.org/10.1111/j.1551-2916.2008.02556.x.

(4) Zubko, P.; Gariglio, S.; Gabay, M.; Ghosez, P.; Triscone, J.-M. Interface Physics in Complex Oxide Heterostructures. Annu. Rev. Condens. Matter Phys. 2011, 2 (1), 141165. https://doi.org/10.1146/annurev-conmatphys-062910-140445.

(5) Moure, C.; Peña, O. Recent Advances in Perovskites: Processing and Properties. Prog. Solid State Chem. 2015, 43 (4), 123-148.

https://doi.org/10.1016/j.progsolidstchem.2015.09.001.

(6) Chamberland, B. L.; Danielson, P. S. Alkaline-Earth Vanadium (IV) Oxides Having AVO3 Composition. J. Solid State Chem. 1971, 3 (2), 243-. https://doi.org/10.1016/0022-4596(71)90035-1.

(7) Giannakopoulou, V.; Odier, P.; Bassat, J. M.; Loup, J. P. SrVO3 and Sr2VO4, Electrical-Properties below and above Room-T. Solid State Commun. 1995, 93 (7), 579-583. https://doi.org/10.1016/0038-1098(94)00834-Y.

(8) Moyer, J. A.; Eaton, C.; Engel-Herbert, R. Highly Conductive SrVO3 as a Bottom Electrode for Functional Perovskite Oxides. Adv. Mater. 2013, 25 (26), 3578-3582. https://doi.org/10.1002/adma.201300900.

(9) Zhang, L.; Zhou, Y.; Guo, L.; Zhao, W.; Barnes, A.; Zhang, H.-T.; Eaton, C.; Zheng, Y.; Brahlek, M.; Haneef, H. F.; Podraza, N. J.; Chan, M. H. W.; Gopalan, V.; Rabe, K. M.; Engel-Herbert, R. Correlated Metals as Transparent Conductors. Nat. Mater. 2015, 15 (2), 204-210. https://doi.org/10.1038/nmat4493.

(10) Mirjolet, M.; Vasili, H. B.; López-Conesa, Ll.; Estradé, S.; Peiró, F.; Santiso, J.; Sánchez, F.; Machado, P.; Gargiani, P.; Valvidares, M.; Fontcuberta, J. Independent Tuning of Optical Transparency Window and Electrical Properties of Epitaxial SrVO3 Thin Films by Substrate Mismatch. Adv. Funct. Mater. 2019, 29 (37), 1904238. https://doi.org/10.1002/adfm.201904238.

(11) Mirjolet, M.; Sánchez, F.; Fontcuberta, J. High Carrier Mobility, Electrical Conductivity, and Optical Transmittance in Epitaxial SrVO3 Thin Films. Adv. Funct. Mater. 2019, 29 (14), 1808432. https://doi.org/10.1002/adfm.201808432.

(12) Boileau, A.; Cheikh, A.; Fouchet, A.; David, A.; Escobar-Galindo, R.; Labbé, C.; Marie, P.; Gourbilleau, F.; Lüders, U. Optical and Electrical Properties of the Transparent Conductor SrVO3 without Long-Range Crystalline Order. Appl. Phys. Lett. 2018, 112 (2), 021905. https://doi.org/10.1063/1.5016245. 
(13) Boileau, A.; Cheikh, A.; Fouchet, A.; David, A.; Labbé, C.; Marie, P.; Gourbilleau, F.; Lüders, U. Tuning of the Optical Properties of the Transparent Conducting Oxide SrVO3 by Electronic Correlations. Adv. Opt. Mater. 2019, 7 (7), 1801516. https://doi.org/10.1002/adom.201801516.

(14) Megaw, H. D. Crystal Structure of Double Oxides of the Perovskite Type. Proc. Phys. Soc. Lond. 1946, 58 (326), 133-. https://doi.org/10.1088/0959-5309/58/2/301.

(15) Range, K.; Rau, F.; Klement, U. High-Pressure Synthesis and Structure Refinement of SrVO3, Sr2VO4, and Sr3V2O7. Z. Naturforschung Sect. B- J. Chem. Sci. 1991, 46 (10), 1315-1318.

(16) Rey, M.; Dehaudt, P.; Joubert, J.; Lambertandron, B.; Cyrot, M.; Cyrot-Lackmann, F. Preparation and Structure of the Compounds SrVO3 and Sr2VO4. J. Solid State Chem. 1990, 86 (1), 101-108. https://doi.org/10.1016/0022-4596(90)90119-I.

(17) Garcia-Jaca, J.; Mesa, J. L.; Insausti, M.; Larramendi, J. I. R.; Arriortua, M. I.; Rojo, T. Synthesis, Crystal Structure, Stoichiometry and Magnetic Properties of (Ca1XSrx)VO3. Mater. Res. Bull. 1999, 34 (2), 289-301. https://doi.org/10.1016/S00255408(99)00002-1.

(18) Dougier, P.; Fan, J.; Goodenough, J. Study of Magnetic, Electrical and OpticalProperties of Phases of Perovskite Structure SrVO2.90 and SrVO3. J. Solid State Chem. 1975, 14 (3), 247-259. https://doi.org/10.1016/0022-4596(75)90029-8.

(19) Li, J.; Yin, D.; Li, Q.; Sun, R.; Huang, S.; Meng, F. Interfacial Defects Induced Electronic Property Transformation at Perovskite SrVO3/SrTiO3 and LaCrO3/SrTiO3 Heterointerfaces. Phys. Chem. Chem. Phys. 2017, 19 (10), 6945-6951. https://doi.org/10.1039/c6cp07691b.

(20) Kim, D. W.; Kim, D. H.; Noh, T. W.; Char, K.; Park, J. H.; Lee, K. B.; Kim, H. D. Interface Chemistry and Electrical Properties of SrVO3/LaAlO3 Heterostructures. $J$. Appl. Phys. 2000, 88 (12), 7056-7059. https://doi.org/10.1063/1.1326896.

(21) Fouchet, A.; Rault, J. E.; Allain, M.; Berini, B.; Rueff, J.-P.; Dumont, Y.; Keller, N. Interface Chemical and Electronic Properties of LaAlO3/SrVO3 Heterostructures. $J$. Appl. Phys. 2018, 123 (5), 055302. https://doi.org/10.1063/1.4998004.

(22) Bourlier, Y.; Berini, B.; Fregnaux, M.; Fouchet, A.; Aureau, D.; Dumont, Y. Transfer of Epitaxial SrTiO3 Nanothick Layers Using Water-Soluble Sacrificial Perovskite Oxides. Acs Appl. Mater. Interfaces 2020, 12 (7), 8466-8474.

https://doi.org/10.1021/acsami.9b21047.

(23) Berini, B.; Demange, V.; Bouttemy, M.; Popova, E.; Keller, N.; Dumont, Y.; Fouchet, A. Control of High Quality SrVO3 Electrode in Oxidizing Atmosphere. Adv. Mater. Interfaces 2016, 3 (18), 1600274. https://doi.org/10.1002/admi.201600274.

(24) Germanicus, R. C.; Bourlier, Y.; Notot, V.; Bérini, B.; Demange, V.; Berthe, M.; Boileau, A.; Euchin, M.; Dumont, Y.; Aureau, D.; Fregnaux, M.; Grandidier, B.; Lüders, U.; David, A.; Prellier, W.; Biadala, L.; Fouchet, A. Three Dimensional Resistance Mapping of Self-Organized Sr3V2O8 Nanorods on Metallic Perovskite SrVO3 Matrix. Appl. Surf. Sci. 2020, 510, 145522. https://doi.org/10.1016/j.apsusc.2020.145522.

(25) Yaremchenko, A. A.; Brinkmann, B.; Janssen, R.; Frade, J. R. Electrical Conductivity, Thermal Expansion and Stability of Y- and Al-Substituted SrVO3 as Prospective SOFC Anode Material. Solid State Ion. 2013, 247, 86-93. https://doi.org/10.1016/j.ssi.2013.06.002.

(26) Macias, J.; Yaremchenko, A. A.; Frade, J. R. Redox Transitions in Strontium Vanadates: Electrical Conductivity and Dimensional Changes. J. Alloys Compd. 2014, 601, 186-194. https://doi.org/10.1016/j.jallcom.2014.02.148. 
(27) Bourlier, Y.; Frégnaux, M.; Bérini, B.; Fouchet, A.; Dumont, Y.; Aureau, D. Surface

Characterizations and Selective Etching of Sr-Rich Segregation on Top of SrVO3 ThinFilms Grown by Pulsed Laser Deposition. ChemNanoMat 2019, 5 (5), 674-681. https://doi.org/10.1002/cnma.201900017.

(28) Han, Z. W.; Wang, Z.; Feng, X. M.; Li, B.; Mu, Z. Z.; Zhang, J. Q.; Niu, S. C.; Ren, L. Q. Antireflective Surface Inspired from Biology: A Review. Biosurface Biotribology 2016, 2 (4), 137-150. https://doi.org/10.1016/j.bsbt.2016.11.002.

(29) Dey, P.; Saha, S. K.; Chakraborty, S. Surface Nanostructure-Wettability Coupling Leads to Unique Topological Evolution Dictating Water Transport over Nanometer Scales. Langmuir 2020, 36 (28), 8111-8122. https://doi.org/10.1021/acs.langmuir.0c00955.

(30) Lacotte, M.; David, A.; Pravarthana, D.; Grygiel, C.; Rohrer, G. S.; Salvador, P. A.; Velazquez, M.; de Kloe, R.; Prellier, W. Growth of Ca2MnO4 Ruddlesden-Popper Structured Thin Films Using Combinatorial Substrate Epitaxy. J. Appl. Phys. 2014, 116 (24), 245303. https://doi.org/10.1063/1.4905012.

(31) Lacotte, M.; David, A.; Rohrer, G. S.; Salvador, P. A.; Prellier, W. Preferential Orientation Relationships in Ca2MnO4 Ruddlesden-Popper Thin Films. J. Appl. Phys. 2015, 118 (4), 045306. https://doi.org/10.1063/1.4927518.

(32) Pravarthana, D.; Lebedev, O. I.; Hebert, S.; Chateigner, D.; Salvador, P. A.; Prellier, W. High-Throughput Synthesis of Thermoelectric Ca3Co4O9 Films. Appl. Phys. Lett. 2013, 103 (14), 143123. https://doi.org/10.1063/1.4824212.

(33) Pravarthana, D.; Chateigner, D.; Lutterotti, L.; Lacotte, M.; Marinel, S.; Dubos, P. A.; Hervas, I.; Hug, E.; Salvador, P. A.; Prellier, W. Growth and Texture of Spark Plasma Sintered A12O3 Ceramics: A Combined Analysis of X-Rays and Electron Back Scatter Diffraction. J. Appl. Phys. 2013, 113 (15), 153510. https://doi.org/10.1063/1.4802439.

(34) Pravarthana, D.; Trassin, M.; Chu, J. H.; Lacotte, M.; David, A.; Ramesh, R.; Salvador, P. A.; Prellier, W. BiFeO3/La0.7Sr0.3MnO3 Heterostructures Deposited on Spark Plasma Sintered LaAlO3 Substrates. Appl. Phys. Lett. 2014, 104 (8), 082914. https://doi.org/10.1063/1.4867021.

(35) Pravarthana, D.; Lebedev, O. I.; David, A.; Fouchet, A.; Trassin, M.; Rohrer, G. S.; Salvador, P. A.; Prellier, W. Metastable Monoclinic [110] Layered Perovskite Dy2Ti2O7 Thin Films for Ferroelectric Applications. RSC Adv. 2019, 9 (35), 1989519904. https://doi.org/10.1039/C9RA04554F.

(36) Woo, S.; Jeong, H.; Lee, S. A.; Seo, H.; Lacotte, M.; David, A.; Kim, H. Y.; Prellier, W.; Kim, Y.; Choi, W. S. Surface Properties of Atomically Flat Poly-Crystalline SrTiO3. Sci. Rep. 2015, 5 (1), 8822. https://doi.org/10.1038/srep08822.

(37) Woo, S.; Lee, S. A.; Mun, H.; Choi, Y. G.; Zhung, C. J.; Shin, S.; Lacotte, M.; David, A.; Prellier, W.; Park, T.; Kang, W. N.; Lee, J. S.; Kim, S. W.; Choi, W. S. Enhanced Magnetic and Thermoelectric Properties in Epitaxial Polycrystalline SrRuO3 Thin Films. Nanoscale 2018, 10 (9), 4377-4384. https://doi.org/10.1039/C7NR09627E.

(38) Pravarthana, D.; Lebedev, O. I.; Hebert, S.; Chateigner, D.; Salvador, P. A.; Prellier, W. High-Throughput Synthesis of Thermoelectric Ca3Co4O9 Films. Appl. Phys. Lett. 2013, 103 (14), 143123. https://doi.org/10.1063/1.4824212.

(39) Pravarthana, D.; Chateigner, D.; Lutterotti, L.; Lacotte, M.; Marinel, S.; Dubos, P. A.; Hervas, I.; Hug, E.; Salvador, P. A.; Prellier, W. Growth and Texture of Spark Plasma Sintered A12O3 Ceramics: A Combined Analysis of X-Rays and Electron Back Scatter Diffraction. J. Appl. Phys. 2013, 113 (15), 153510. https://doi.org/10.1063/1.4802439.

(40) Dhanapal, P.; Guo, S.; Wang, B.; Yang, H.; Agarwal, S.; Zhan, Q.; Li, R.-W. HighThroughput Investigation of Orientations Effect on Nanoscale Magnetization Reversal 
in Cobalt Ferrite Thin Films Induced by Electric Field. Appl. Phys. Lett. 2017, 111 (16), 162401. https://doi.org/10.1063/1.4996375.

(41) Demange, V.; Bérini, B.; Gautier, B.; Popova, E.; Dumont, Y.; Fouchet, A. Ca3(VO4)2 Nanowires on Metallic CaVO3 Films as Nanocapacitors. ACS Appl. Nano Mater. 2020, 3 (7), 6684-6692. https://doi.org/10.1021/acsanm.0c01136.

(42) Eaton, C.; Moyer, J. A.; Alipour, H. M.; Grimley, E. D.; Brahlek, M.; LeBeau, J. M.; Engel-Herbert, R. Growth of SrVO3 Thin Films by Hybrid Molecular Beam Epitaxy. $J$. Vac. Sci. Technol. A 2015, 33 (6), 061504. https://doi.org/10.1116/1.4927439.

(43) P. Hirsch, A. Howie, R. Nicholson, D. W. Pashley and M. J. Whelan. Electron Microscopy of Thin Crystals; Butterworths/Krieger, London/Malabar FL, 1965.

(44) Gibert, M.; García, A.; Puig, T.; Obradors, X. Thermodynamic Stability Analysis of Isometric and Elongated Epitaxial Ce1-XGdxO2-y Nanostructures on Perovskite Substrates. Phys. Rev. B 2010, 82 (16), 165415. https://doi.org/10.1103/PhysRevB.82.165415.

(45) Obradors, X.; Puig, T.; Gibert, M.; Queraltó, A.; Zabaleta, J.; Mestres, N. Chemical Solution Route to Self-Assembled Epitaxial Oxide Nanostructures. Chem. Soc. Rev. 2014, 43 (7), 2200-2225. https://doi.org/10.1039/C3CS60365B.

(46) Gibert, M.; Abellán, P.; Benedetti, A.; Puig, T.; Sandiumenge, F.; García, A.; Obradors, X. Self-Organized Ce1-XGdxO2-y Nanowire Networks with Very Fast Coarsening Driven by Attractive Elastic Interactions. Small 2010, 6 (23), 2716-2724. https://doi.org/10.1002/smll.201001237.

(47) Queraltó, A.; De la Mata, M.; Arbiol, J.; Hühne, R.; Obradors, X.; Puig, T. Unveiling the Nucleation and Coarsening Mechanisms of Solution-Derived Self-Assembled Epitaxial Ce0.9Gd0.1O2-y Nanostructures. Cryst. Growth Des. 2017, 17, 504-516. https://doi.org/10.1021/acs.cgd.6b01358. 

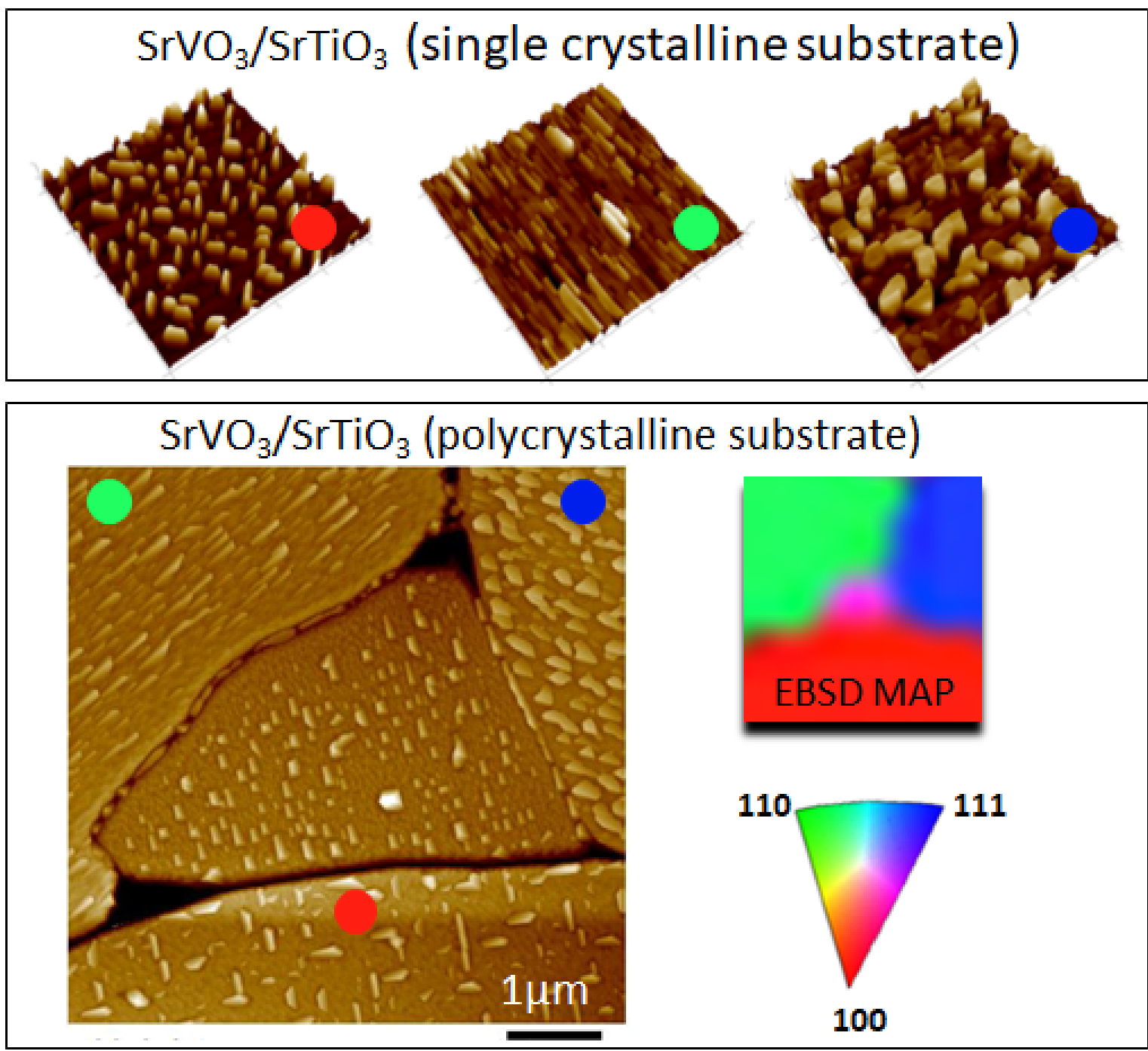

Self-organized $\mathrm{Sr}_{3} \mathrm{~V}_{2} \mathrm{O}_{8}$ nanostructures on $\mathrm{SrVO}_{3}$ thin film

Graphical abstract 
1
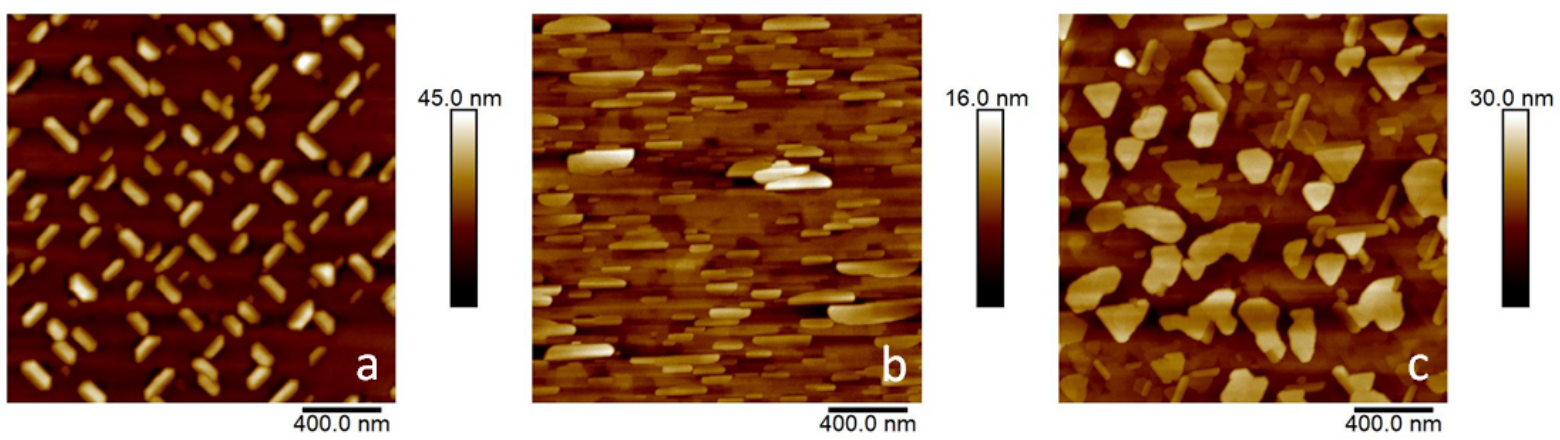

Figure 1. AFM images of the surface of a SVO film grown on three single crystalline STO substrates with the following orientations: a) (100), b) (110), and c) (111). $\mathrm{Sr}_{3} \mathrm{~V}_{2} \mathrm{O}_{8} \mathrm{NS}$ are observed with different shapes and sizes. 

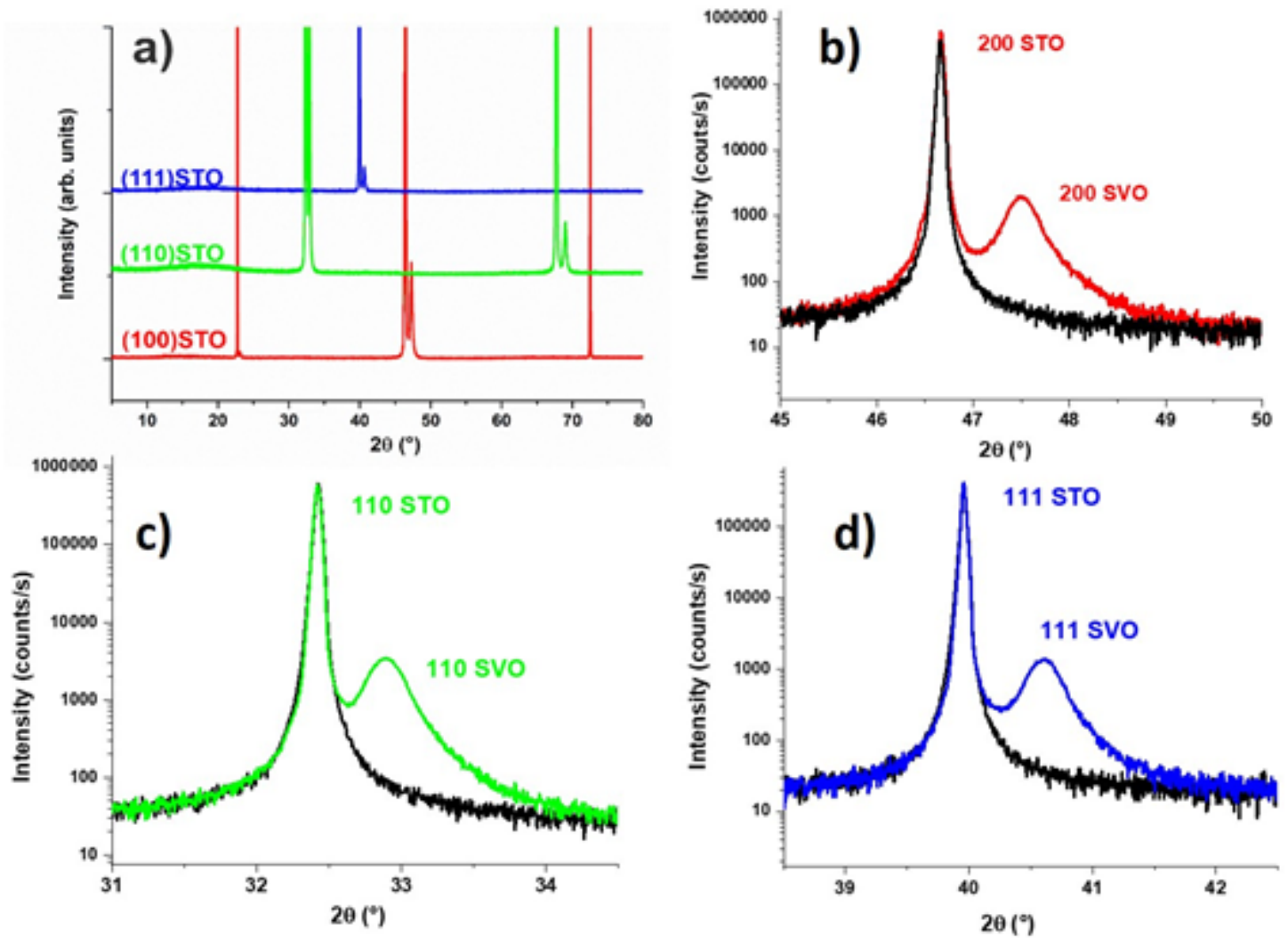

Figure 2. XRD patterns of the SVO films grown on various substrates: (a) full angular range pattern of films grown on (100)-, (110)- and (111)STO. b) Pattern of film grown on (100)STO around the (200) reflection (log. scale). c) Pattern of film grown on (110)STO around the (110) reflection (log. scale). d) Pattern of film grown on (111)STO around the (111) reflection (log. scale). A color code is adopted from EBSD where red line corresponds to SVO onto (100)STO, green line for (110)STO and blue line for (111)STO. For b,c,d, in black is the reference substrate without film. 

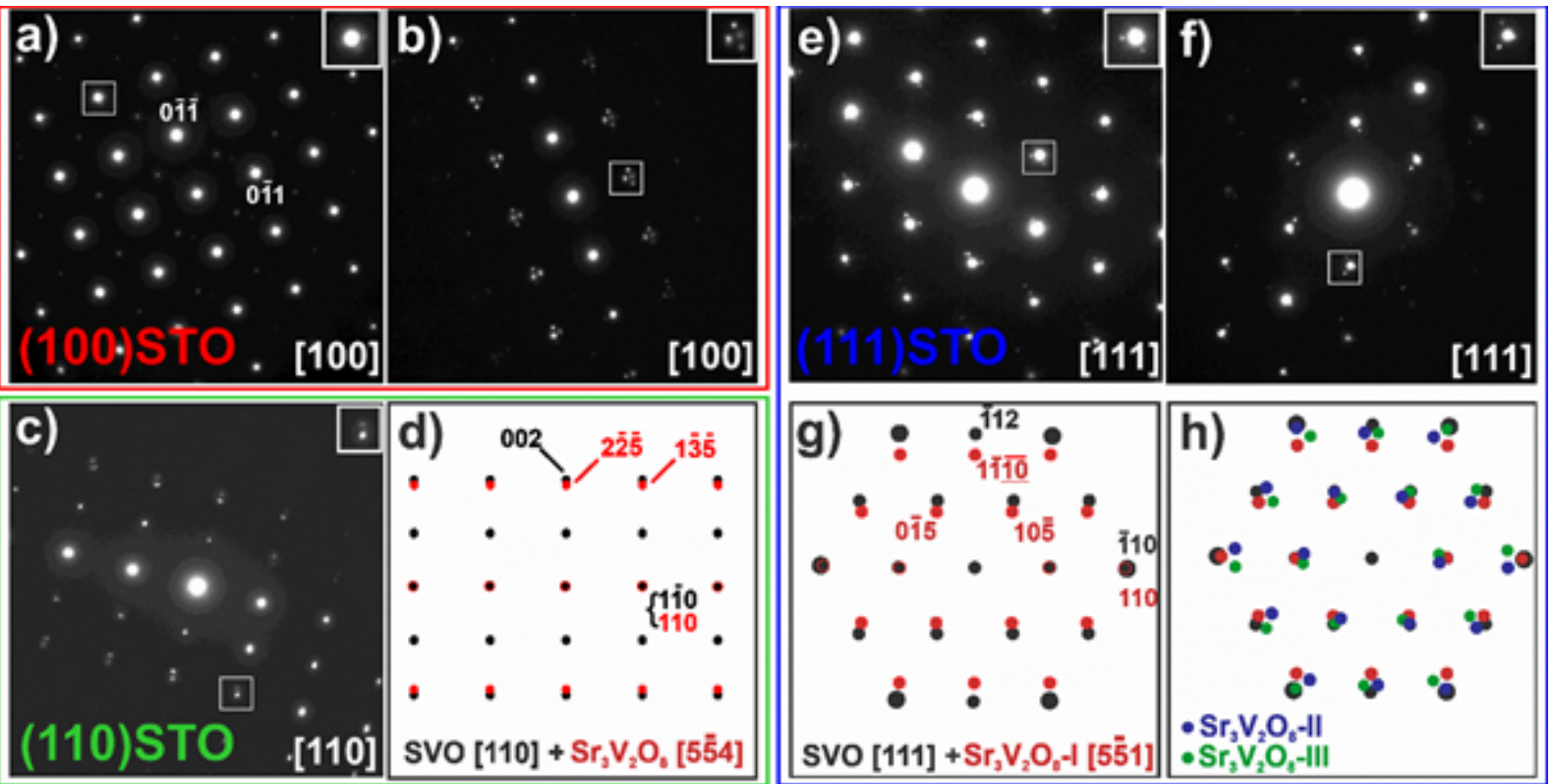

Figure 3. EDPs along the [100] zone axis (a) and slightly tilted from the zone axis (b) of the (100)SVO film displaying additional $\mathrm{Sr}_{3} \mathrm{~V}_{2} \mathrm{O}_{8} \mathrm{NS}$ weak reflections close to the strong $\mathrm{SVO}$ reflections, magnified in the insets. c) EDP slightly tilted from the [110]SVO zone. d) Scheme of the experimental EDP: reflections and labels of the SVO phase are displayed in black, those of the $\mathrm{Sr}_{3} \mathrm{~V}_{2} \mathrm{O}_{8}$ phase are displayed in red. e),f) EDPs of the SVO films slightly tilted from the [111]SVO zone axis, showing three series of weak reflections due to the $\mathrm{Sr}_{3} \mathrm{~V}_{2} \mathrm{O}_{8} \mathrm{NS}$ oriented along the [55 1$]$ out-of-plane direction. $g$ ) Scheme of the EDP of the SVO film with reflections of one $\mathrm{Sr}_{3} \mathrm{~V}_{2} \mathrm{O}_{8}$ variant (black: $\mathrm{SVO}$; red: first variant the $\mathrm{Sr}_{3} \mathrm{~V}_{2} \mathrm{O}_{8}$ of phase). h) Same with reflections of the three $\mathrm{Sr}_{3} \mathrm{~V}_{2} \mathrm{O}_{8}$ variants (black: $\mathrm{SVO}$; red, green, blue: the $3 \mathrm{Sr}_{3} \mathrm{~V}_{2} \mathrm{O}_{8}$ variants). 


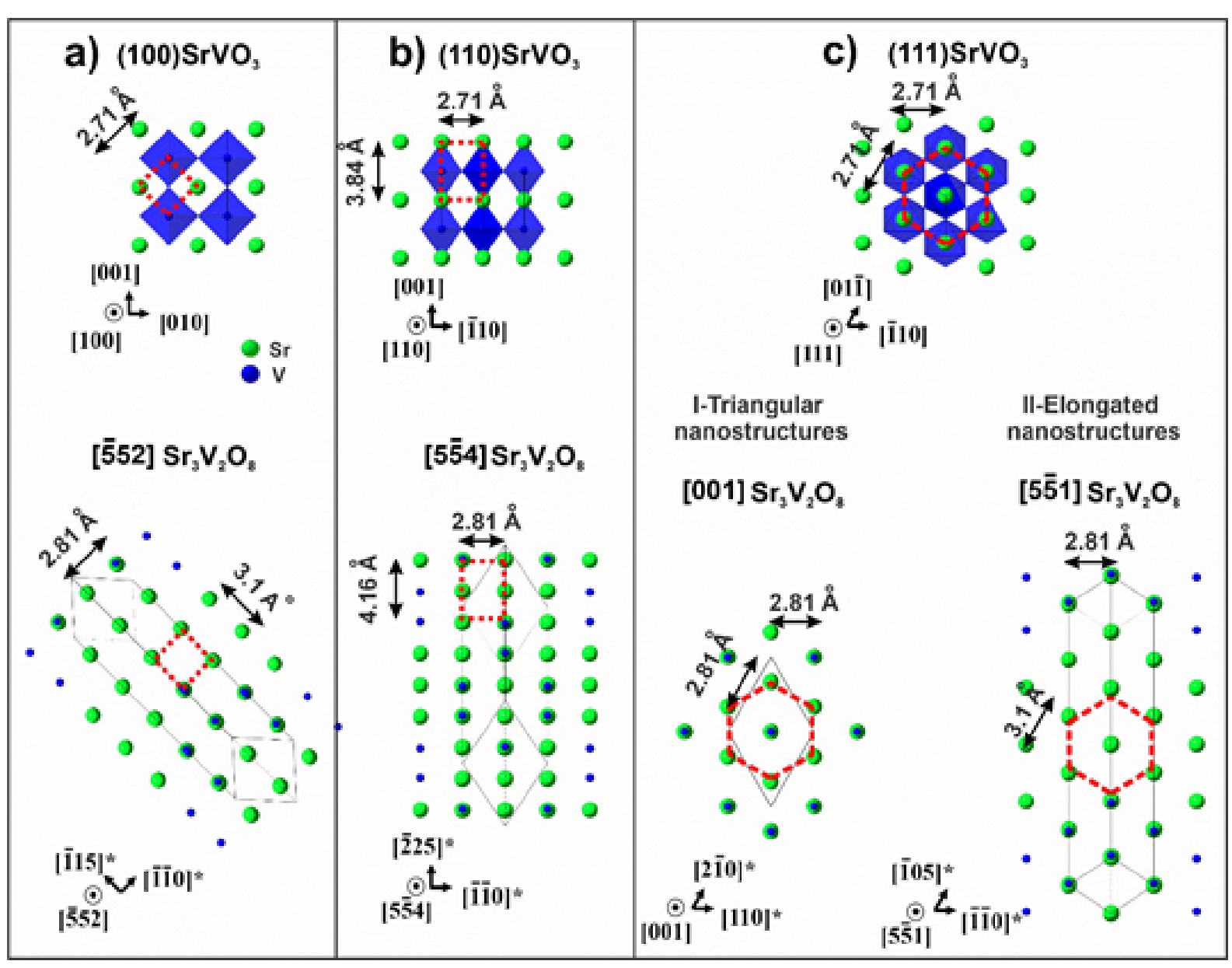

Figure 4. a) Schemes of the epitaxial relationships between the SVO phase (top part) and the $\mathrm{Sr}_{3} \mathrm{~V}_{2} \mathrm{O}_{8}$ phase (bottom part) on 100(STO) (a), (110)STO (b) and (111)STO (c). The in-plane coincidence cell for both phases is defined by dashed red lines for each orientation. 


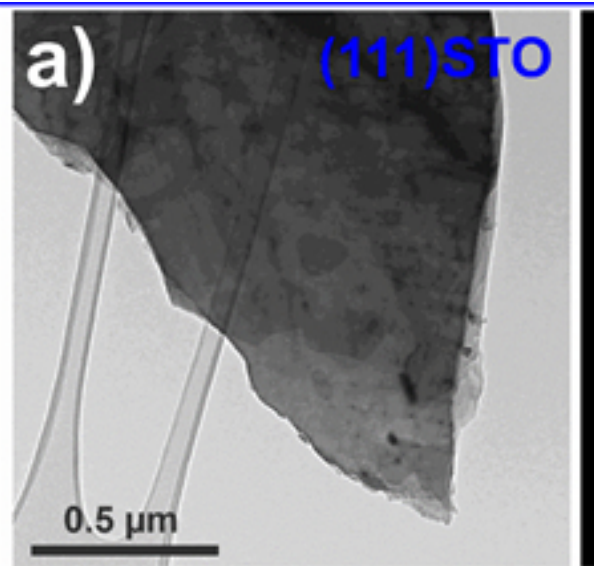

b)
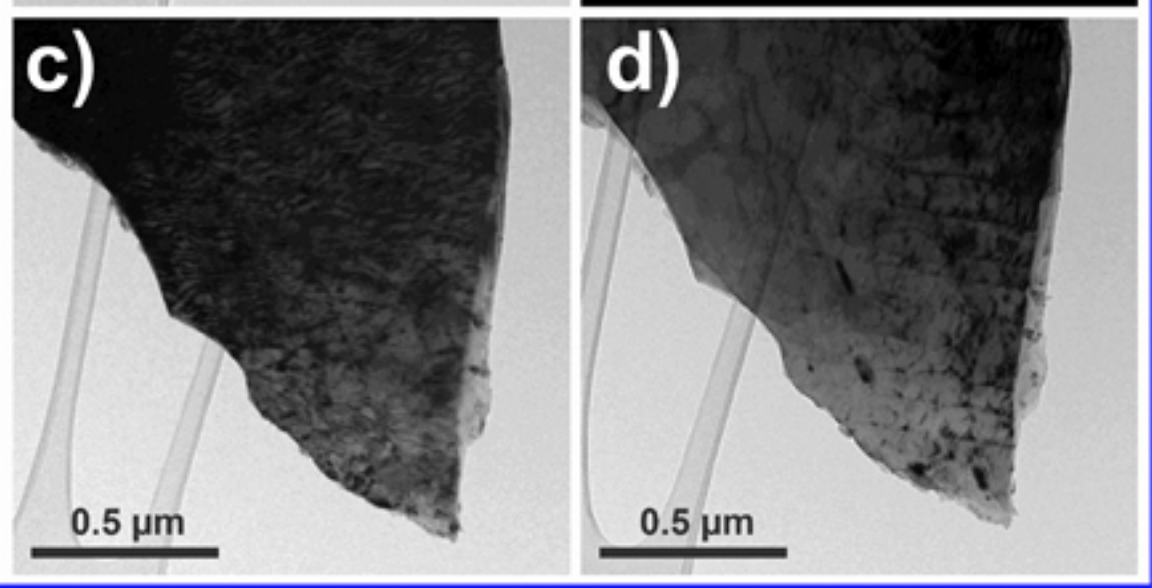

Figure 5. a) Bright field image of a fragment of the SVO film grown on (111)STO. b) EDP along the [111] zone axis of SVO. c) Bright field of the same area slightly tilted and showing Moiré fringes. d) Same with another tilt allowing to see the elongated $\mathrm{Sr}_{3} \mathrm{~V}_{2} \mathrm{O}_{8} \mathrm{NS}$. 


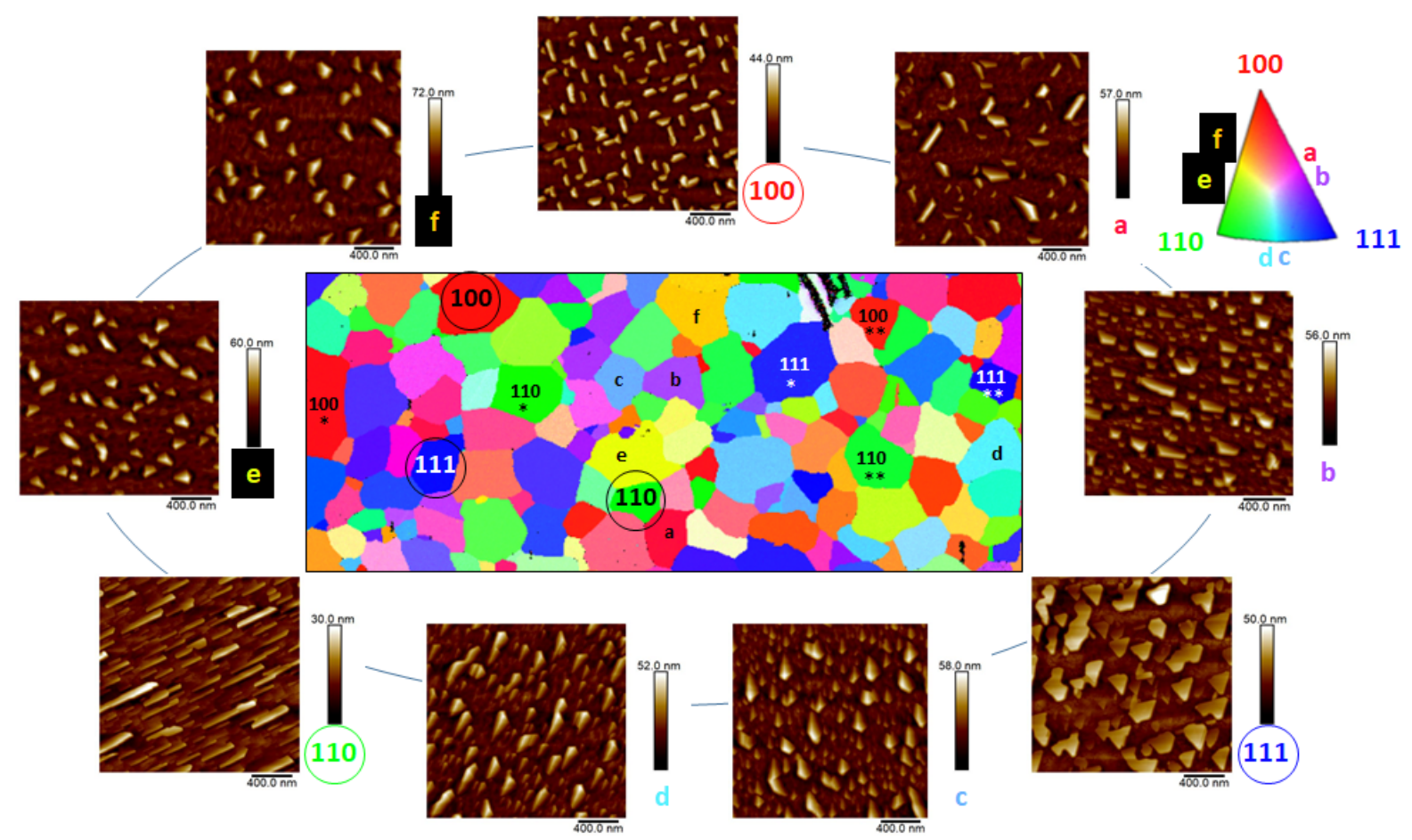

Figure 6. AFM images of selected grains of the SVO film onto the polycrystalline substrate having preferential (100), (110) and (111) out-of-plane orientations and intermediate orientations. 

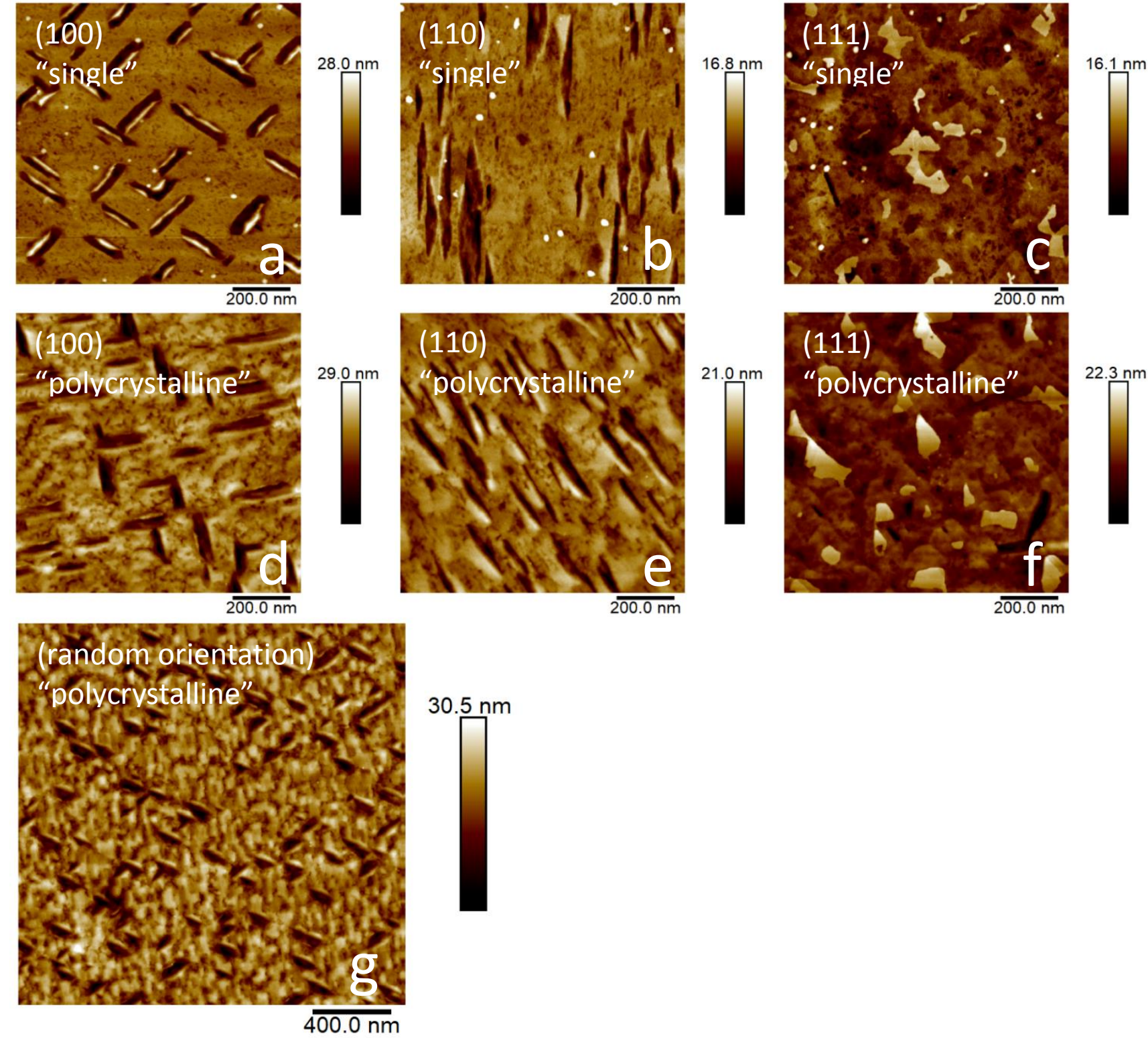

Figure 7. In first row, are presented AFM images of SVO films grown onto (100), (110) and (111)STO single crystalline substrates after dissolution of the NS (a), (b), (c) respectively and in second row, onto the polycrystalline substrate after dissolution of the NS for the three standard orientations (100), (100) and (111), (d), (e), (f), respectively. The last image (g) corresponds to a non-conventional orientation (yellow colored grain noted e in figure 6 as observed in EBSD map). 
Click here to access/download

Supplementary Material for on-line publication only
SI-revised bb-VD.docx 


\section{Author contributions}

B.B. and A.F. conceived and designed the experiments. B.B. synthesized the films by PLD and M.D. synthetized CSE substrates. V.D. and L.R. performed XRD and TEM measurements and analyzed all the measurements. B.B. performed AFM characterizations and analyzed with R.C.G. all AFM measurements. M.D. performed and analyzed with A.D. EBSD measurements. Y.B. performed the electrical transport measurements and analyzed with Y.D. the results. W.P., U.L., Y.D. have leadership responsibilities. B.B., M.D, V.D. and A.F. wrote the original manuscript with inputs from all authors. 